\title{
Lessons from monitoring, screening, evaluation and early detection of breast cancer in Iran
}

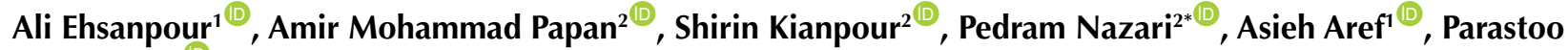 \\ Ahangpour ${ }^{2}$
}

${ }^{1}$ Thalassemia and Hemoglobinopathy Research Center, Research Institute of Health, Ahvaz Jundishapur University of Medical Sciences, Ahvaz, Iran

${ }^{2}$ Cancer Research Center, Ahvaz Jundishapur University of Medical Sciences, Ahvaz, Iran

Correspondence to:

Pedram Nazari,

Email: nazari.p@ajums.ac.ir

Received: 26 Aug. 2021 Accepted: 14 Oct. 2021 ePublished: 5 Nov. 2021

Citation: Ehsanpour A,
Papan AM, Kianpour
S, Nazari P, Aref A,
Ahangpour P. Lessons
from monitoring,
screening, evaluation and
early detection of breast
cancer in Iran. J Prev
Epidemiol. 2022;7(1):e12.
doi: 10.34172/
jpe.2022.12.

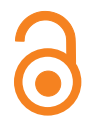

\begin{abstract}
Key point
On The evaluation and monitoring of the screening and early detection program of breast cancer have a key role in cancer management. For this purpose, we proposed a new approach to evaluating the screening program. According to this method, if new cases were identified with or without screening, they consider as the success or failure of the screening program, respectively. This feedback loop is complete with identifying each geographical area's defects and solves their specific problems.

Keywords: Monitoring, Breast Cancer, Screening program
\end{abstract}

B reast cancer is an important health issue all over the world and based on the Iranian National Populationbased Cancer Registry the most recent surveys show the age-specific incidence rate for breast cancer to be about 34.53 per 100000 (1). Unfortunately, most cases are not diagnosed until advanced stages when curative initiatives are impossible and only palliative care can be given (2). This matter has dramatically worsened when we factor in the increasing rate of cancers in Iran which have been predicted to be 6.9 in 2020 and $115.7 \%$ in 2040 (compared to other countries: $5.0 \%$ in 2020 and $63.4 \%$ in 2040) (3).

To combat these issues, improvement of cancer management, and better allocation of funds, the Iranian Health Ministry, designed the Iran National Cancer Care Network (INCCN) in 2013. Subsequently, the Document of Development of Cancer Care Network was approved. All these actions lead to Iran being introduced as a fast-track in control of non-communicable diseases by World Health Organization in 2018 September. One of the most prominent aspects of this program is related to screening and early diagnosis of breast cancer. The national screening and early detection of breast cancer program are based in each government founded university of medical sciences and the program is based on coordination of three deputies within the medical university: Deputy of Health, Treatment, and Research (in Iran the public health and medical universities are tightly linked and public health is delivered through these establishments). In this program, first, the primary health center (PHC) of Health Deputy assesses the target population including all females between the ages of 30 to 69 years old or individuals with any sign or symptoms related to breast complaints from any age by expert midwives. In step 2, the suspicious cases will be referred to Cancer Screening and Early Detection Center (type 1 center) of Treatment Deputy for more evaluations which include but are not limited to surgeon visits, breast mammography, or ultrasound according to national breast cancer guideline (Iran's Package of essential NCD (IraPEN) interventions for primary health care) (4). Finally, Cancer Registry records confirmed new cases of cancer in a special online web-based system (Simaye-saratan) that is updated in real-time (Figure 1).

Monitoring, screening, early detection, and subsequent evaluation of the program are key aspects of this plan on both local and national levels. Monitoring refers to continuous assessment of the quality of the ongoing process and the performance of the project based on the objectives of this plan. Monitoring of the programs helps the project manager to solve everyday issues much more quickly (WHO, 2017). Unfortunately, 


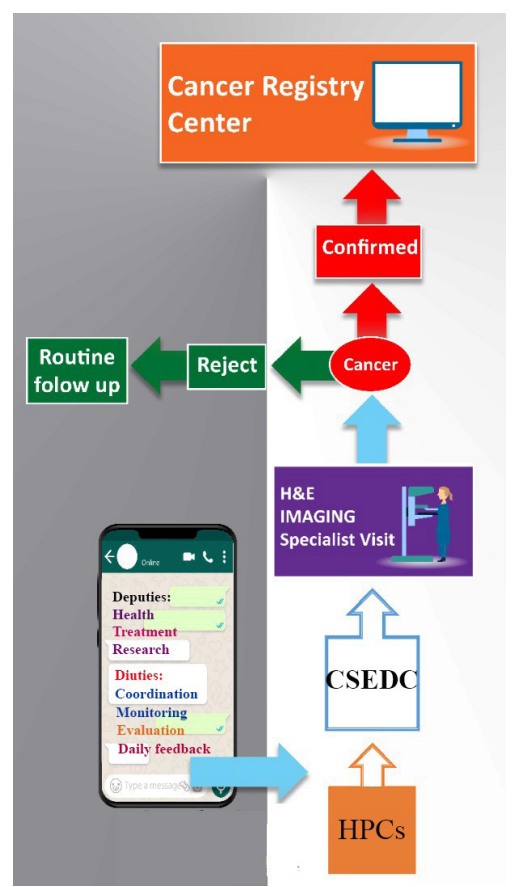

Figure 1. The conceptual map of the national program of screening and early detection of breast cancer. HPCs; Health Primary Care Center, CSEDC: Cancer Screening and Early Detection Center, H\&E; History and Physical Examination

one of the most challenging aspects of management of national programs in developing counties is related to the lack of suitable and systematic monitoring plans due to administrative bureaucracy and segmented and unlinked management. When this program began, despite several internal meetings with the aim of raising awareness for the program staff, no sufficient feedback was existed and the program worked very slowly. Lack of constructive supervision and explanation of the crucial role of PHC staff and their important role that can make or break the entire program lead to underutilization of resources and less timely referral for the patients. Therefore, it was decided to use social media as a cheaper alternative to proprietary software. Using this virtual group all managers and staff who were involved in the program participated. The activity (the number of referred individuals) of each PHC was reported in the group, daily. Thereby, the activities of each part of the system were accessible to the managers and supervisors of the program in real-time. This process led to better communications among team members. After implementing this process for only one week the primary aims were reached. Currently, the usage of smartphones and related technologies such as social media and different messenger applications (like WhatsApp) has expanded a lot. This application can help developing countries without sufficient infrastructure to better utilize and distribute information in a user-friendly and easy-to-work method. It seems that the usage of this application can lead to better and faster communication, monitoring, and management of a program in communities with significant due process (5).

Evaluation refers to the assessment of the efficacy of the program in achieving its intended goals in a timely fashion usually 1 to 2 years after the start of the program. Several parameters help evaluate a new screening program, these include but are not limited to; the screening test, cost, intervention, advantages, and disadvantages of the screening program. There are not many tools available for the evaluation of a new screening program (6). For this purpose, we decided to compare the result of newly registered cancer patients from data available from the cancer registry database. If new cases were identified by screening, this meant that the program was successful. On the other hand, if new cases were diagnosed with another method meaning without screening, this meant that our screening program has failed to reproduce results. The next step consists of identifying each geographical area and solves their specific problems. This feedback loop can fine-tune the project in the long run and help reduce the higher-stage cancer workups and costs associated with it.

Authors' contribution

AE, AMP, SK, PA and AA conducted the literature search and prepared the first draft. PN conducted the edit and is the corresponding author. All authors read and signed the final paper.

\section{Conflicts of interest}

The authors have declared no conflict of interest.

\section{Ethical issues}

Ethical issues (including plagiarism, data fabrication, double publication) have been completely observed by the authors.

Funding/Support

None.

\section{References}

1. Roshandel G, Ghanbari-Motlagh A, Partovipour E, Salavati F, Hasanpour-Heidari S, Mohammadi G, et al. Cancer incidence in Iran in 2014: results of the Iranian National Populationbased Cancer Registry. Cancer Epidemiol. 2019;61:50-8. doi: 10.1016/j.canep.2019.05.009.

2. Rivera-Franco MM, Leon-Rodriguez E. Delays in Breast Cancer Detection and Treatment in Developing Countries. Breast Cancer (Auckl). 2018;12:1178223417752677. doi: 10.1177/1178223417752677.

3. Bray F, Ferlay J, Soerjomataram I, Siegel RL, Torre LA, Jemal A. Global cancer statistics 2018: GLOBOCAN estimates of incidence and mortality worldwide for 36 cancers in 185 countries. CA Cancer J Clin. 2018;68:394-424. doi: 10.3322/ caac. 21492 .

4. Shrivastava SR, Shrivastava PS, Ramasamy J. Implementing the world health organization's package of essential noncommunicable disease interventions in primary care settings. J Sci Soc. 2017;44:165.

5. De Benedictis A, Lettieri E, Masella C, Gastaldi L, Macchini G, Santu C, Tartaglini D. WhatsApp in hospital? An empirical investigation of individual and organizational determinants to use. PLoS One. 2019;14:e0209873. doi: 10.1371/journal. pone.0209873.

6. Pasick RJ, Hiatt RA, Paskett ED. Lessons learned from community-based cancer screening intervention research. Cancer. 2004;101:1146-64. doi: 10.1002/cncr.20508. 